\title{
Defensive Responses of Cuttlefish to Different Teleost Predators
}

\author{
MICHELLE D. STAUDINGER ${ }^{\mathrm{a}, \mathrm{b}, *}$, KENDRA C. BURESCH ${ }^{\mathrm{c}}$, LYDIA M. MÄTHGER ${ }^{\mathrm{c}}$, \\ CHARLIE FRY ${ }^{\mathrm{c}}$, SARAH MCANULTY ${ }^{\mathrm{c}}$, KIMBERLY M. ULMER ${ }^{\mathrm{c}}$, AND ROGER T. HANLON ${ }^{\mathrm{c}}$ \\ ${ }^{\mathrm{a}}$ DOI Northeast Climate Science Center, 134 Morrill Science Center, University of Massachusetts, \\ Amherst, Massachusetts 01003-9297; ${ }^{\mathrm{b}}$ Missouri Cooperative Fish and Wildlife Research Unit, \\ Department of Fisheries and Wildlife Sciences, University of Missouri, Columbia, Missouri 65211; \\ ${ }^{\mathrm{c}}$ Program in Sensory Physiology and Behavior, Marine Biological Laboratory, 7 MBL Street, Woods \\ Hole, Massachusetts 02543
}

\begin{abstract}
We evaluated cuttlefish (Sepia officinalis) responses to three teleost predators: bluefish (Pomatomus saltatrix), summer flounder (Paralichthys dentatus), and black seabass (Centropristis striata). We hypothesized that the distinct body shapes, swimming behaviors, and predation tactics exhibited by the three fishes would elicit markedly different antipredator responses by cuttlefish. Over the course of 25 predator-prey behavioral trials, 3 primary and 15 secondary defense behaviors of cuttlefish were shown to predators. In contrast, secondary defenses were not shown during control trials in which predators were absent. With seabass-a benthic, sit-and-pursue predator-cuttlefish used flight and spent more time swimming in the water column than with other predators. With bluefish—an active, pelagic searching predator-cuttlefish remained closely associated with the substrate and relied more on cryptic behaviors. Startle (deimatic) displays were the most frequent secondary defense shown to seabass and bluefish, particularly the Dark eye ring and Deimatic spot displays. We were unable to evaluate secondary defenses by cuttlefish to flounder-a lie-and-wait predator-because flounder did not pursue cuttlefish or make attacks. Nonetheless, cuttlefish used primary defense during flounder trials, alternating between cryptic still and moving behaviors. Overall, our results suggest that cuttlefish may vary their behavior in the presence of different teleost predators: cryptic behaviors may be more important in the presence of active searching predators (e.g., bluefish), while conspicuous movements
\end{abstract}

Received 10 April 2013; accepted 2 December 2013.

* To whom correspondence should be addressed. E-mail: mstaudinger @usgs.gov such as swimming in the water column and startle displays may be more prevalent with relatively sedentary, bottomassociated predators (e.g., seabass).

\section{Introduction}

Antipredator behaviors are generally categorized as either primary or secondary defenses (Cott, 1940; Robinson, 1969; Edmunds, 1974). Primary defense consists of cryptic behaviors that reduce the probability of detection or recognition by predators. After detection and recognition by a predator has occurred, secondary defenses are employed, and animals must choose between "stay" or "flee" tactics to disrupt the attack sequence and escape an impending threat (Young, 1950; Edmunds, 1974; Hanlon and Messenger, 1996). Acute body patterns or postures that cause predators to hesitate during the approach phase of an attack through frightening, startling, or bluffing are known as "deimatic displays" and are typically shown from a fixed position (the stay tactic) (Cott, 1940; Young, 1950; Edmunds, 1974; Endler, 1991). Deimatic spots are a common display shown by cephalopods, fishes, insects, and amphibians; they are intended to deceive predators into perceiving a larger, more dangerous animal (Hanlon and Messenger, 1996; LenziMattos et al., 2005; Vallin et al., 2007). Alternatively, flee tactics use rapid locomotion to move away from a threat and are believed to be the most common antipredator responses employed by animals under natural conditions (Humphries and Driver, 1970). Erratic and unpredictable behaviors, known as "protean defense," increase the potential for escape by confusing predators and retarding their ability to predict the location of fleeing prey (Driver and Humphries, 
1988; Domenici et al., 2008). Protean behaviors in cephalopods are often used in conjunction with locomotion (Hanlon and Messenger, 1996; Staudinger et al., 2011). For example, the ink-blanch-jet maneuver, which is used by many cephalopods, combines rapid color change, inking, and irregular swimming or jetting to confound the escape trajectory as the animal moves away from a threat (Hanlon and Messenger, 1988, 1996).

Ultimately, the risk posed by each type of predator determines which behavioral defense is utilized to maximize survivorship (Schmitz, 2005; Hoverman and Relyea, 2007; Stuart-Fox et al., 2008). This includes factors such as the size, speed, and directness with which different predators approach their prey, predator density (e.g., group size), the defense capabilities of the prey (e.g., camouflage, swimming speed, age), and environmental factors such as the complexity of the environment and distance to refuge (Stankowich and Blumstein, 2005; Michel and Adams, 2009). In some cases, it may be more effective to avoid predation by fleeing as soon as a predator approaches; in others, movement may alert the predator to a prey's presence and be more likely to evoke an attack (Broom and Ruxton, 2005; Stankowich and Blumstein, 2005). Additionally, some predators may be more responsive to bluffing, thus deimatic behaviors may be advantageous both as a deterrent and as a means to conserve energy that would have been expended during escape by fleeing or active protean maneuvers.

Coleoid cephalopods, which include squids, cuttlefish, and octopods, are prevalent in global marine environments and serve as an important prey resource to a wide range of fishes, marine mammals, birds, and other invertebrates including conspecifics (Lipinski and Jackson, 1989; Hanlon and Messenger, 1996; Blanc and Daguzan, 2000; Staudinger and Juanes, 2010a). Extant species within this taxonomic group are soft-bodied and lack morphological structures such as shells or spines, which are common defenses in other prey animals (vertebrates, e.g., fish; invertebrates, e.g., snails, sea urchins) and increase protection by making them more difficult to capture and ingest. This vulnerability may have influenced selective forces leading to the evolution of complex behaviors in coleoid cephalopods; these behaviors consist of chromatic, textural, postural, and locomotor components, and are involved in the signaling or avoidance of predators and conspecifics (Packard, 1972; Hanlon and Messenger, 1988, 1996; Huffard, 2006; Wood et al., 2008; Mäthger et al., 2012).

Cephalopods that live in shallow-water habitats (e.g., the photic zone) are thought to largely depend on primary defense (i.e., crypsis) for protection, as many predators within these environments use vision to hunt (Hanlon and Messenger, 1988, 1996). Cuttlefish, Sepia officinalis in particular, lend themselves to the study of camouflage and other antipredator behaviors because they can rapidly change their appearance in response to environmental and threatening stimuli (Hanlon and Messenger, 1988). Upon being placed on a given background, they immediately respond by employing a body pattern that best disguises the animal. This chromatic response provides a powerful biological assay to study the way these animals perceive their visual environment (Chiao and Hanlon, 2001; Barbosa et al., 2004, 2007, 2008; Mäthger et al., 2006, 2007, 2008; Kelman et al., 2007, 2008; Chiao et al., 2010; Zylinski et al., 2009a, b). Laboratory experiments have provided insight into visual cues that elicit change in cuttlefish body patterns, textures, and postures for camouflage, yet there is limited evidence of how these and other antipredator behaviors are directly influenced by the threat posed by different types of predators. Interactions between cephalopods and their predators are rarely observed in the field (but see Hanlon and Messenger, 1988; Mather, 2010), and only a few laboratory studies have reported direct observations of attack behaviors and antipredator responses with real predators (Langridge et al., 2007; Langridge, 2009; Staudinger and Juanes, 2010b, c; Staudinger et al., 2011).

In the present study, we evaluate the primary and secondary defense responses shown by the European cuttlefish (S. officinalis (Linnaeus, 1758)) to three species of teleost predators: bluefish (Pomatomus saltatrix (Linnaeus, 1766)), summer flounder (Paralichthys dentatus (Linnaeus, 1766)), and black seabass (Centropristis striata (Linnaeus, 1758)), that exemplify distinct body shapes, swimming behaviors, and predation tactics. Bluefish are a roving predator with a fusiform body morphology; they hunt actively in schools for prey in the water column and near the bottom (Staudinger and Juanes, 2010c). Flounder have a compressed body form, spend the majority of their lives on or near the bottom, and are primarily solitary, lie-and-wait predators (Staudinger and Juanes, 2010b). Seabass are a deep-bodied fish that use a variety of sit-and-pursue tactics, including ambush, following, and stalking behaviors, to capture prey in demersal habitats (Schmitz, 2005; Gibran, 2007). Seabass were considered to represent an intermediate hunting mode compared to bluefish (active) and flounder (ambush), and may be solitary or occur in shoals (Steimle et al., 1999). We hypothesized that the threat posed from each species of teleost would elicit markedly different antipredator behaviors by cuttlefish. Here, we provide a qualitative analysis of prey defensive responses and of predator behaviors, preand post-attack.

\section{Materials and Methods}

The European cuttlefish (Sepia officinalis) is native to the eastern Atlantic and Mediterranean oceans. However, due to difficulties in importing eastern Atlantic teleost fishes internationally, three western Atlantic analogs of predators that cuttlefish would normally encounter in the wild were used 
in experimental trials: bluefish, seabass, and flounder. We expected that cuttlefish would recognize black seabass and summer flounder as potential predators because they have body shapes and behaviors similar to those of two of their natural predators from the eastern Atlantic Ocean and Mediterranean Sea-comber (Serranus cabrilla) and Atlantic halibut (Hippoglossus hippoglossus), respectively (Hanlon and Messenger, 1996; Blanc and Daguzan, 2000; Muus and Nielsen, 1999). Bluefish occur in the eastern Atlantic Ocean and utilize habitats similar to cuttlefish; however, there is limited information about predator-prey interactions in this region (Juanes et al., 1996). Nonetheless, it was expected that cuttlefish would perceive bluefish as a threat because this species has a body form (fusiform) common to many aggressive pelagic predators (e.g., sharks, tunas, jacks).

In addition, bluefish, seabass, and flounder were chosen for predator-prey trials because they consume cephalopods as a regular part of their diets in western Atlantic waters (Steimle et al., 1999; Bowman et al., 2000; Staudinger, 2006; Staudinger and Juanes, 2010a). During preliminary and experimental trials, black seabass and bluefish showed aggressive, predatory behaviors towards cuttlefish, and flounder exhibited behaviors typical of an animal preparing to make a predatory attack (e.g., displayed a raised pectoral fin, pointed vertically) (Staudinger and Juanes, 2010b). Consequently, we were confident that these species recognized cuttlefish as potential prey.

\section{Animal collection, care, and experimental use}

Summer flounder and black seabass were collected from Vineyard and Nantucket Sounds aboard the RV Gemma in May 2009 using an otter-trawl. Bluefish were caught by hook-and-line from coastal waters near Woods Hole, Massachusetts, in August 2009 (Department of Marine Fisheries Scientific Permit Number 152087). Differences in collection methods, seasonal availability, and amount of tank space necessary to maintain healthy populations of fishes in captivity over the course of this study caused slight disparities in the size range and numbers of individuals obtained for each species. Thirty-five seabass (mean total length $(\mathrm{TL})=35 \mathrm{~cm}$ ), 10 bluefish (mean TL $=40 \mathrm{~cm}$ ), and 14 flounder (mean TL $=60 \mathrm{~cm}$ ) were housed at the Marine Resources Center (MRC) at the Marine Biological Laboratory (MBL), for use in predator-prey trials. Each species was housed separately and fed a mixed diet of frozen squid and fish. Animals were allowed to acclimate to captivity for several weeks prior to use in behavioral trials. When the majority of fish from each species were feeding regularly they were considered sufficiently acclimated to captivity and ready for use in behavioral trials.

Cuttlefish were hatched, reared, and maintained at the MRC at the MBL. An initial population of 20 cuttlefish ranging in size from 5 to $7 \mathrm{~cm}$ in mantle length (ML) was used in behavioral trials. Over the time-period when behavioral trials were conducted (August 2009-February 2010), five cuttlefish died (primarily due to injury or predation during trials), and the body sizes of cuttlefish in our captive population varied due to growth. Cuttlefish used during initial trials conducted in August 2009 with seabass were about 5-7 cm in ML. We used two cuttlefish in each seabass trial. During trials with bluefish (conducted in November and December 2009), and flounder (conducted during January 2010), fewer cuttlefish remained in our population and individuals had roughly doubled in body size (ML ranged from 10 to14 cm). These changes in our captive population reduced the total number of appropriately sized cuttlefish (e.g., within the range of commonly consumed predatorprey body-size ratios: Scharf et al., 2000; Staudinger and Juanes, 2010a, b, c) available during later trials. Consequently, we used only one cuttlefish during trials with bluefish and flounder to reduce the number of times an individual cuttlefish was used in the overall number of trials conducted. All animals were cared for and experiments were conducted in accordance with the regulations of the MBL Institutional Animal Care and Use Committees.

\section{Experimental arena}

Predator-prey behavioral trials with seabass were conducted in a $178 \times 61 \mathrm{~cm}$ (diameter, height) tank. Because bluefish and flounder were larger and used more active predation tactics than seabass, trials with these two predators were conducted in a $310 \times 80 \mathrm{~cm}$ tank. All tanks were filled with recirculating and biofiltered seawater between 16 and $20^{\circ} \mathrm{C}$, and maintained on a 12:12-h light/dark schedule. The bottoms of experimental tanks were covered with a $2.5-5.0-\mathrm{cm}$ layer of natural substrate consisting of a mixture of sand, pebbles, and rock collected from local beaches. This substrate is typical of the natural habitats of the animals used in this study and permitted flounder and cuttlefish to camouflage and bury. Experimental tanks were surrounded with black plastic to reduce disturbance to the animals.

\section{Cuttlefish camouflage control trials: behaviors in the absence of predators}

In a preliminary experiment conducted in 2007, we evaluated cuttlefish camouflage behavior on the same natural substrate and in tanks similar to those used in the predatorprey trials reported in this paper. The camouflage responses of eight cuttlefish, ranging in size from 7 to $12 \mathrm{~cm}$ in ML, to natural substrates were evaluated in the absence of predators, and results serve as a control experiment of cuttlefish behavior in an unthreatening environment. In each trial, a single cuttlefish was placed in the experimental arena and allowed to acclimate. An animal was considered acclimated when it settled on the substrate, ceased to swim around the 


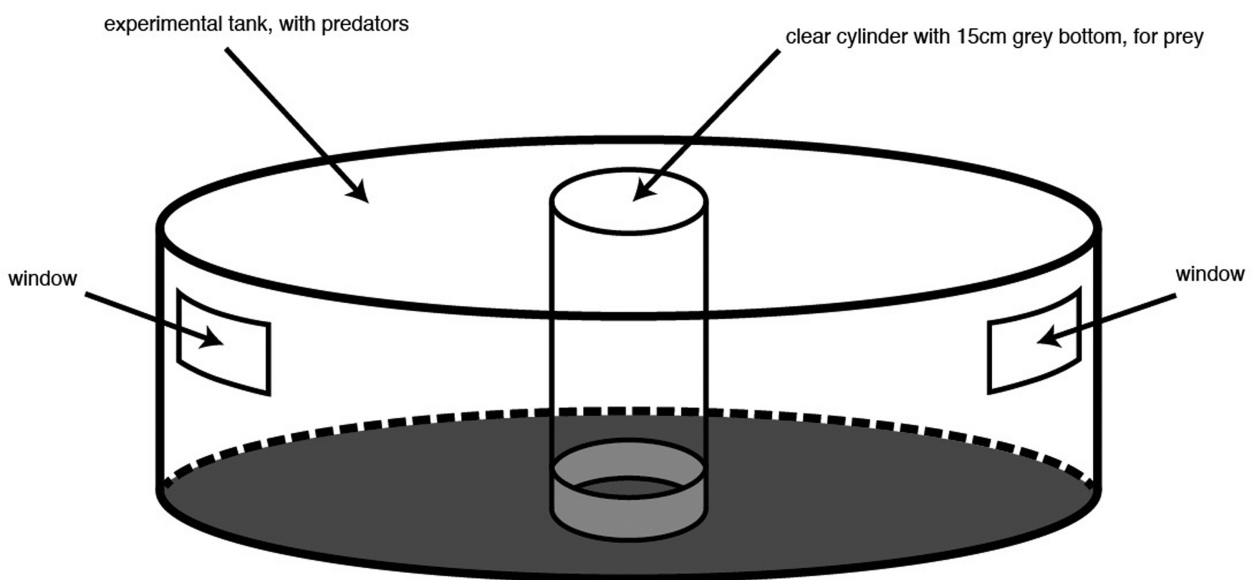

Figure 1. The experimental tank set-up.

tank, and showed a stable camouflage pattern and regular breathing movements (about $15 \mathrm{~min}$ ). Photographs were then taken using an underwater still-shot camera (Pentax Optio W20) of the animal's camouflage pattern on natural substrates.

\section{Predator-prey trials}

For each predator-prey behavioral trial, either three seabass, three bluefish, or two flounder were randomly sampled, with replacement after testing, from their respective captive population and moved from holding tanks into the experimental tank to acclimate. Individual fish were reused in more than one trial; however, care was taken to separate fishes used after each trial from the remaining individuals in their respective predator population so that the same individuals were not used in consecutive trials. An individual bluefish or flounder may thus have been used up to five times over the course of trials (10 trials with flounder and 9 with bluefish), and an individual seabass could have been used a maximum of three times over all trials (six trials total). We felt that the time elapsed between potential repeated reuse of individuals (4 days) was sufficient to minimize potential predator learning. Due to the limited number of cuttlefish in our captive population $(n=15-20)$, it was also necessary to reuse individuals over the course of all trials. Cuttlefish were rotated between two holding tanks as they were used in trials, so that all individuals were used once before any were reused; an individual cuttlefish was not used more than once every 4 weeks and thus about once with each type of predator.

Three bluefish or seabass were used in each predator-prey trial because this number of individuals has been shown to allow for normal schooling and feeding behaviors of roving fishes (Juanes and Conover, 1994; Scharf et al., 1998; Staudinger and Juanes, 2010c). Although flounder are considered solitary animals, previous experiments (Staudinger and Juanes, 2010b, c, 2011) have shown that these lie-andwait predators may not move for hours and may not attack unless a prey is within a single body length. Having multiple flounder in a tank creates more competition and will often encourage fish to be more aggressive. Unfortunately, flounder still made no attacks during trials with cuttlefish, and thus the difference between using one or two fish did not put the cuttlefish at a disadvantage.

After fish were moved from holding tanks to the experimental arena, food was withheld for a minimum of $18 \mathrm{~h}$ to standardize hunger levels. About $1 \mathrm{~h}$ prior to the start of each trial, a PVC cylinder (36-cm diameter, $80-\mathrm{cm}$ height) was lowered into the center of the experimental tank, and cuttlefish were placed inside the cylinder to acclimate. The PVC cylinder was opaque on the lower half to conceal cuttlefish that had settled on the substrate, and clear on the top half so that we could determine prior to starting a trial whether cuttlefish were active (or settled), and thus visible to predators at the start of each trial. If cuttlefish had not settled on the substrate after the 1-h acclimation period and were still actively moving around the cylinder, the trial was aborted.

All trials were conducted between the hours of 0800 and 1600. Each trial began when the cylinder was slowly raised out of the tank by a pulley system. Fish and cuttlefish behaviors were filmed for 30 min using two Sony HDR XR-520V video cameras through viewing windows on opposite sides of the experimental tanks (Fig. 1). All animals were removed from experimental tanks immediately after filming and returned to holding tanks.

\section{Behavioral analysis}

Cuttlefish and predator behaviors were evaluated by reviewing video footage recorded during trials. The order and frequency of behaviors shown by cuttlefish was assessed using frame-by-frame video play-back analysis. Cuttlefish 
behaviors were classified as primary or secondary defenses and organized into an ethogram (based largely on Hanlon and Messenger, 1988). Behavioral sequences were recognized as any event in which a predator clearly detected (e.g., displayed changes to swimming speed, raised fins, eye movements) and approached a cuttlefish, or a cuttlefish appeared threatened and showed secondary defense behaviors toward predators. Each sequence was representative of the behaviors shown by a single cuttlefish toward one or more fish (e.g., bluefish schooled together and, as a group, may have influenced cuttlefish behaviors). In addition, behavioral sequences were included only when the behaviors of both fish and prey could be observed throughout the interaction from at least one camera angle. In trials where predators did not appear to detect cuttlefish and no interactions occurred, the entire trial was considered a single sequence and cuttlefish behaviors were classified as primary defense. Initial behaviors shown by cuttlefish as a predator approached were categorized as either "flee" or "stay" tactics; flee tactics included rapid locomotion or protean behaviors, while stay tactics included primary defense and deimatic displays (Driver and Humphries, 1988; Hanlon and Messenger, 1996; Staudinger et al., 2011). The frequency of defense behaviors shown by cuttlefish toward predatory fish were evaluated as (1) initial responses (flee and stay as well as specific secondary defenses), and (2) all primary and secondary behaviors combined. Because of the small sample sizes and reuse of individuals in this study, our results are presented as preliminary and qualitative descriptions of cuttlefish behavioral response toward different types of predators.

\section{Results}

Cuttlefish camouflage control trials: behaviors in the absence of predators

All eight cuttlefish acclimated by settling on the natural substrates within $15 \mathrm{~min}$ of being introduced to the experimental tank. Although cuttlefish often initially moved short distances just above the substrate to resettle themselves, they never swam into the mid or upper portion of the water column during control trials. Cuttlefish were observed to show chromatic body patterns of Uniform/Stipple, Mottle/ Disruptive, and Disruptive while resting just on or buried in the substrate (Fig. 2). Deimatic displays or other secondary defenses were not observed during control trials.

\section{Predator-prey trials}

Over the course of 25 predator-prey behavioral trials, 44 behavioral sequences were evaluated of cuttlefish responses and interactions with seabass, bluefish, and flounder. Three primary and 15 secondary defense behaviors were observed (Table 1), although not all behaviors were shown to all
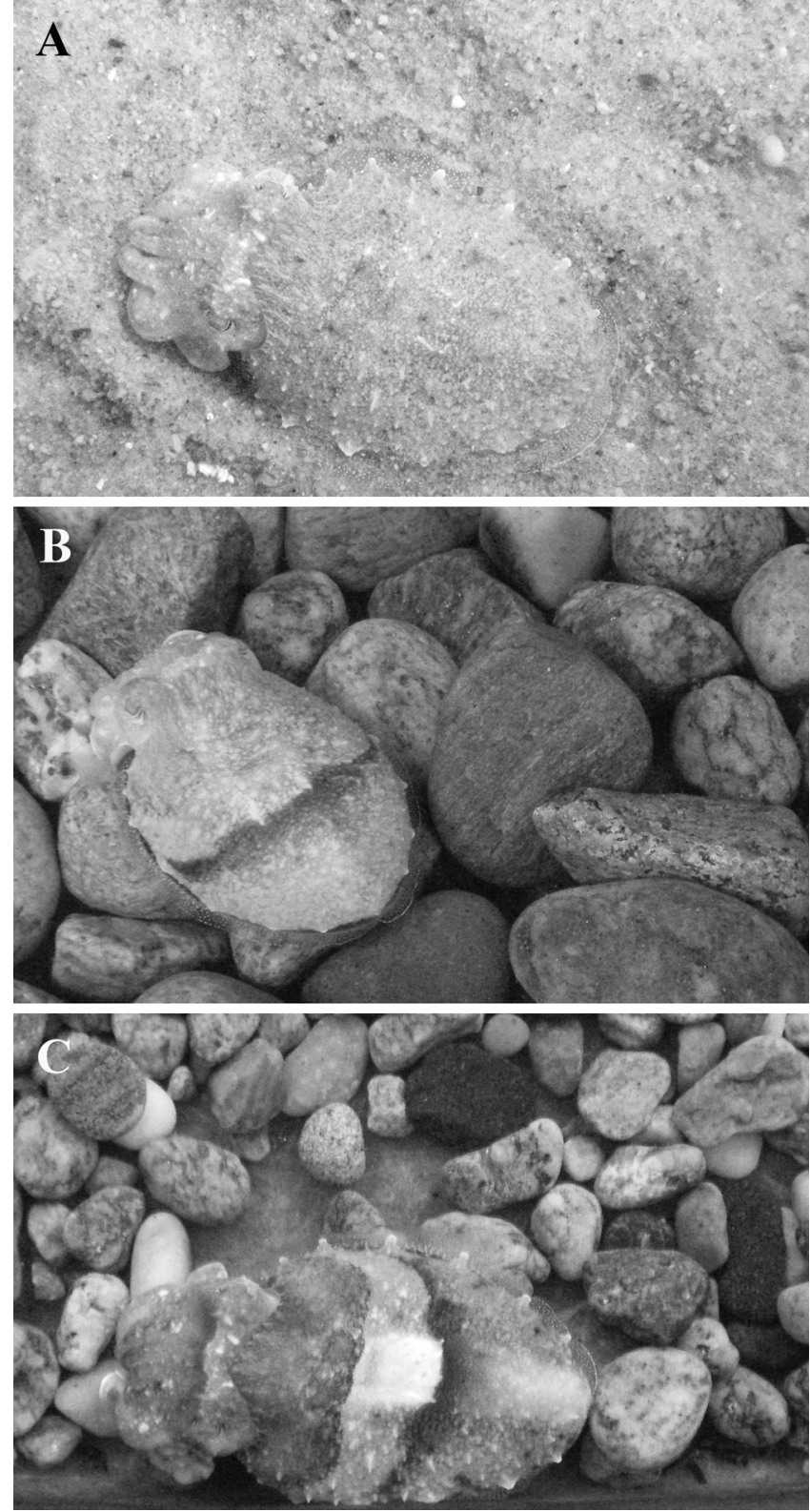

Figure 2. Images from control trials of cuttlefish camouflaging against natural substrates in the absence of predators. (A) Uniform/Stipple, (B) Mottle/Disruptive, and (C) Disruptive body patterns.

predators (Table 2). During three trials, cuttlefish foraged on small crustaceans living in the substrate; two distinctive body pattern and stalking behaviors were observed during these events (see foraging behaviors in Table 1).

\section{Black seabass}

Twenty behavioral sequences were evaluated over the course of six trials with seabass. During trials, seabass rested on the bottom or swam in short, slow movements near the bottom or lower portion of the tank. Seabass 
Table 1

Ethogram of cuttlefish behaviors shown during trials with black seabass, bluefish, and summer flounder

\begin{tabular}{|c|c|c|}
\hline Category & Behavior & Description \\
\hline \multicolumn{3}{|l|}{ Primary defense } \\
\hline & Cryptic still & $\begin{array}{l}\text { Background resemblance to match substrate; sitting or buried motionless } \\
\text { on or in substrate }\end{array}$ \\
\hline & $\begin{array}{l}\text { Deceptive resemblance / } \\
\text { masquerade }\end{array}$ & $\begin{array}{l}\text { Background resemblance to match substrate, sitting motionless on } \\
\text { substrate, arms raised possibly to look like vegetation on the bottom }\end{array}$ \\
\hline & Cryptic moving & $\begin{array}{l}\text { Background resemblance to match substrate with locomotion; hovering } \\
\text { or swimming slowly on or near bottom }\end{array}$ \\
\hline \multicolumn{3}{|r|}{ 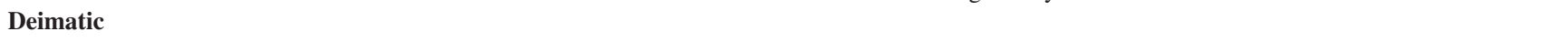 } \\
\hline & Dark mottle & Dark mottle body pattern often with dark fin line \\
\hline & All dark & Entire body uniform dark brown \\
\hline & $\begin{array}{l}\text { White anterior head and } \\
\text { arms }\end{array}$ & $\begin{array}{l}\text { Head and arms white in contrast to mantle, which may be Light or Dark } \\
\text { mottle }\end{array}$ \\
\hline & $\begin{array}{l}\text { Dark anterior head and } \\
\text { arms }\end{array}$ & $\begin{array}{l}\text { Head and arms uniform dark in contrast to mantle, which may be Light } \\
\text { or Dark mottle }\end{array}$ \\
\hline & Dark eye ring & Dark circle around eyes; often shown with Raised head \\
\hline & Deimatic spots & Eye spots on mantle; no movement \\
\hline & $\begin{array}{l}\text { Deimatic spots with } \\
\text { movement }\end{array}$ & $\begin{array}{l}\text { Eye spots displayed on mantle; cuttlefish rotates body toward } \\
\text { approaching predator with Drooping arms and hangs vertically with } \\
\text { mantle pointing downward in water column }\end{array}$ \\
\hline & $\begin{array}{l}\text { Flamboyant display: } \\
\text { Threat posture }\end{array}$ & Hovering in water column with Splayed arms (upward and downward) \\
\hline & $\begin{array}{l}\text { Flamboyant display: } \\
\text { Flattened body } \\
\text { posture }\end{array}$ & Sitting on substrate, Flattened body, with Splayed arms (downward) \\
\hline \multicolumn{3}{|l|}{ Protean } \\
\hline & Erratic jetting & Rapid and erratic Locomotion \\
\hline & Pattern flashing & Acute and repeated color change alternating between dark to light \\
\hline Ink & Inking & Moderate inking \\
\hline & Smoke screen & $\begin{array}{l}\text { Profuse inking; cuttlefish turns All dark and hides in own ink cloud or } \\
\text { plume }\end{array}$ \\
\hline \multicolumn{3}{|l|}{ Flight } \\
\hline & Slow retreat & $\begin{array}{l}\text { Slow swimming along bottom away from threat while showing } \\
\text { background resemblance. }\end{array}$ \\
\hline & Jet away & Rapid jetting away from threat \\
\hline \multicolumn{3}{|c|}{$\begin{array}{l}\text { Cuttlefish foraging-related } \\
\text { behaviors }\end{array}$} \\
\hline & Bipedal locomotion & $\begin{array}{l}\text { Background resemblance to match substrate with locomotion; hovering } \\
\text { just above the substrate, two arms in contact with substrate and used } \\
\text { to "walk" along the bottom }\end{array}$ \\
\hline & $\begin{array}{l}\text { Dark anterior head and } \\
\text { arms }\end{array}$ & $\begin{array}{l}\text { Head and arms uniform dark in contrast to mantle, which may be light } \\
\text { or dark mottle }\end{array}$ \\
\hline
\end{tabular}

Note that not all behaviors were displayed to all predators. Detailed descriptions of cuttlefish behaviors can be found in Hanlon and Messenger (1988, 1996).

generally did not swim into the mid to upper portion of the water column unless they were investigating a cuttlefish that was swimming near the surface. Seabass typically moved independently of each other, but during a few trials they formed loose groups and approached cuttlefish together. Seabass appeared unaware of the presence of cuttlefish in the tank unless the cuttlefish moved. This was evidenced by the fact that seabass never approached or attacked a cuttlefish that was camouflaged and motionless on the substrate. In addition, we observed seabass that, without exhibiting any predatory behaviors, swam above and even rested nearby cuttlefish that were camouflaged or buried on the bottom. When cuttlefish were detected and seabass initiated movement, the seabass oriented toward the cuttlefish, used fin postures (e.g., raised fins) (Fig. 3A), and subsequently approached or stalked the cuttlefish. During the approach phase of an attack, seabass laid down their dorsal fins and paused before lunging toward cuttlefish (Fig. 3B). Deimatic displays and inking by cuttlefish often caused seabass to appear to startle or hesitate, as evidenced by raising dorsal 
Table 2

Total frequency of cuttlefish defense and foraging behaviors shown over the course of 25 trials and 44 behavioral sequences with seabass, bluefish, and flounder

\begin{tabular}{|c|c|c|c|c|}
\hline Category & Behavior & Seabass & Bluefish & Flounder \\
\hline \multirow[t]{4}{*}{ Primary defense } & & 4 & 14 & 10 \\
\hline & Cryptic still & 4 & 10 & 5 \\
\hline & Deceptive resemblance/masquerade & - & 4 & - \\
\hline & Cryptic moving & - & - & 5 \\
\hline \multirow[t]{10}{*}{ Deimatic } & & 51 & 36 & $\mathbf{0}$ \\
\hline & Dark mottle & 11 & 5 & - \\
\hline & All dark & 6 & - & - \\
\hline & White head and arms & - & 3 & - \\
\hline & Dark anterior head and arms & - & 2 & - \\
\hline & Dark eye ring & 23 & 4 & - \\
\hline & Deimatic spots & 5 & 13 & - \\
\hline & Deimatic spots with movement & 1 & 3 & - \\
\hline & Flamboyant display: Threat posture & 3 & 4 & - \\
\hline & $\begin{array}{l}\text { Flamboyant display: Flattened } \\
\text { body posture }\end{array}$ & 2 & 2 & - \\
\hline \multirow[t]{3}{*}{ Protean behavior } & & 4 & 2 & $\mathbf{0}$ \\
\hline & Erratic jetting & 3 & 2 & - \\
\hline & Pattern flashing & 1 & - & - \\
\hline \multirow[t]{3}{*}{ Ink } & & 9 & 4 & $\mathbf{0}$ \\
\hline & Inking & 7 & 2 & - \\
\hline & Smoke screen & 2 & 2 & - \\
\hline \multirow[t]{3}{*}{ Flight } & & 16 & 7 & $\mathbf{0}$ \\
\hline & Slow retreat & 5 & 5 & - \\
\hline & Jet away & 11 & 2 & - \\
\hline \multirow[t]{3}{*}{ Cuttlefish foraging-related behaviors } & & $\mathbf{0}$ & 2 & 2 \\
\hline & Bipedal locomotion & - & 1 & - \\
\hline & Dark anterior head and arms & - & 1 & 2 \\
\hline
\end{tabular}

Seabass ( $n=20$ behavioral sequences from 6 trials), bluefish $(n=14$ behavioral sequences from 9 trials), and flounder $(n=10$ behavioral sequences from 10 trials).

fins, spreading pectoral fins, slowing or halting swimming, and turning away from the cuttlefish.

Cuttlefish appeared to be threatened by the presence of seabass even when seabass movements were not predatory (e.g., a predator changed its swimming direction). This was evidenced by acute body patterns and movements away from seabass. Although predator-prey interactions with seabass were nearly equally as likely to occur in the upper water column $(40 \%, 8 / 20)$ as on the substrate $(45 \%, 9 / 20)$, cuttlefish spent more time swimming near the water surface during trials with seabass than in the presence of any other predator evaluated (Fig. 4). When seabass initiated an attack by making a direct approach, cuttlefish alternated between stay $(60 \%, 12 / 20)$ and flee $(40 \%, 8 / 20)$ tactics as initial responses (Fig. 5). The most frequent initial response was for cuttlefish to remain motionless on the bottom (the stay tactic) and show the deimatic Dark eye ring $(n=16 / 20)$ display (Fig. 6).

Overall, deimatic displays $(n=51)$ were used more than any other defense tactic with seabass (Table 2; Fig. 7), and were highly effective in disrupting the attack sequence, causing seabass to hesitate or turn away from cuttlefish in
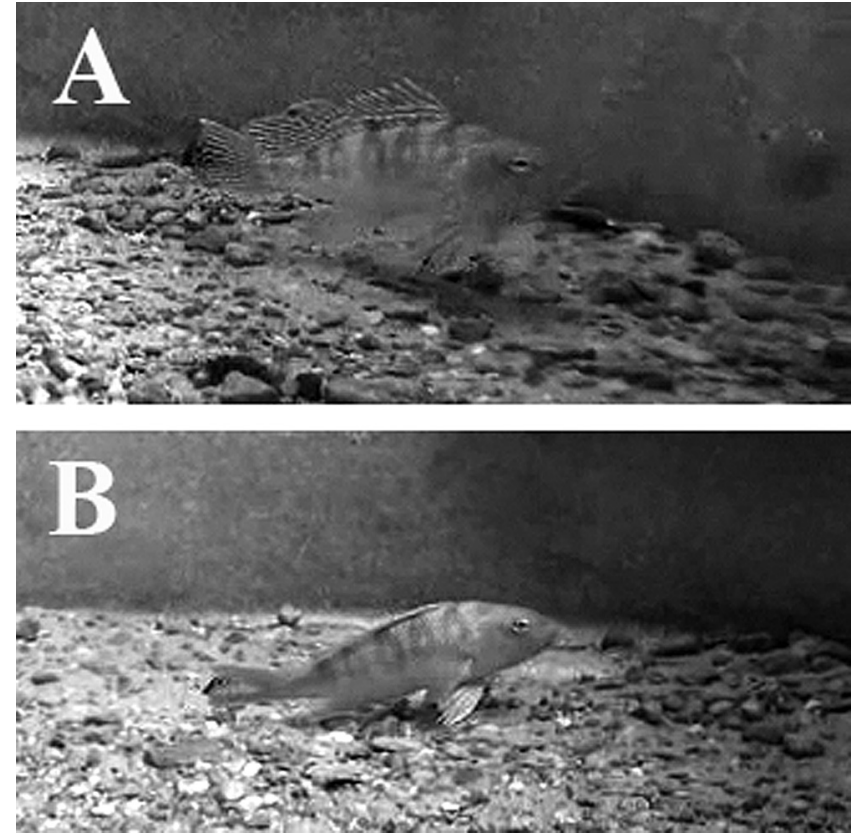

Figure 3. Images taken during behavioral trials of black seabass (A) resting, and (B) just prior to making an attack on cuttlefish. 


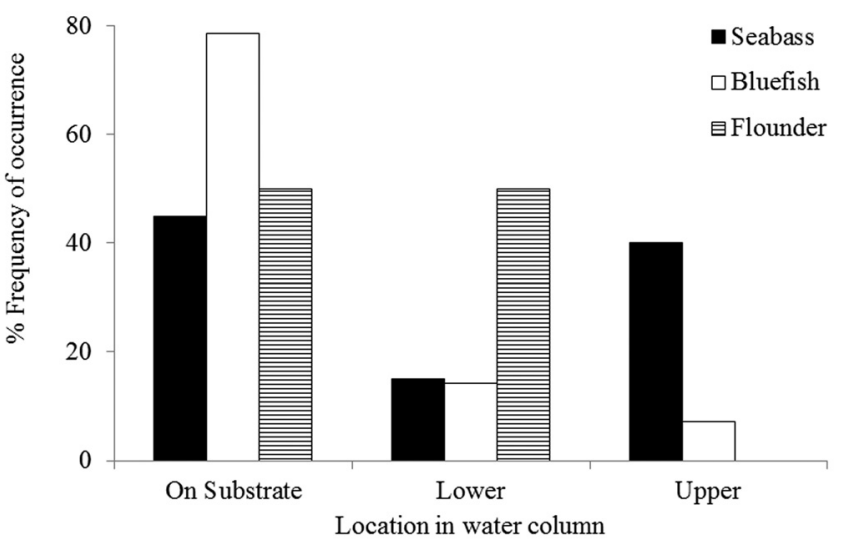

Figure 4. Relative frequencies of locations (substrate, lower and upper water column) where behavioral sequences occurred within experimental tanks between cuttlefish and seabass (filled bar, $n=20$ behavioral sequences from 6 trials); bluefish (open bar, $n=14$ behavioral sequences from 9 trials); or flounder (striped bar, $n=10$ behavioral sequences from 10 trials). On substrate indicates interactions where cuttlefish were resting on the bottom; lower and upper indicate behavioral sequences where cuttlefish swam in the lower or upper half of the water column, respectively.

all but one interaction. Dark eye ring displays $(n=23)$ were particularly important during seabass trials (Table 2), and cuttlefish used this display to make their eyes suddenly appear very conspicuous and large (Fig. 8A) (Video 1: Cuttlefish dark eye ring, http://www.biolbull.org/content/ supplemental). The use of Deimatic spots achieved a similar effect (Fig. 8B), and in a few trials, cuttlefish flashed Deimatic spots on and off or simultaneously showed Dark eye ring and Deimatic spot displays in an apparent attempt

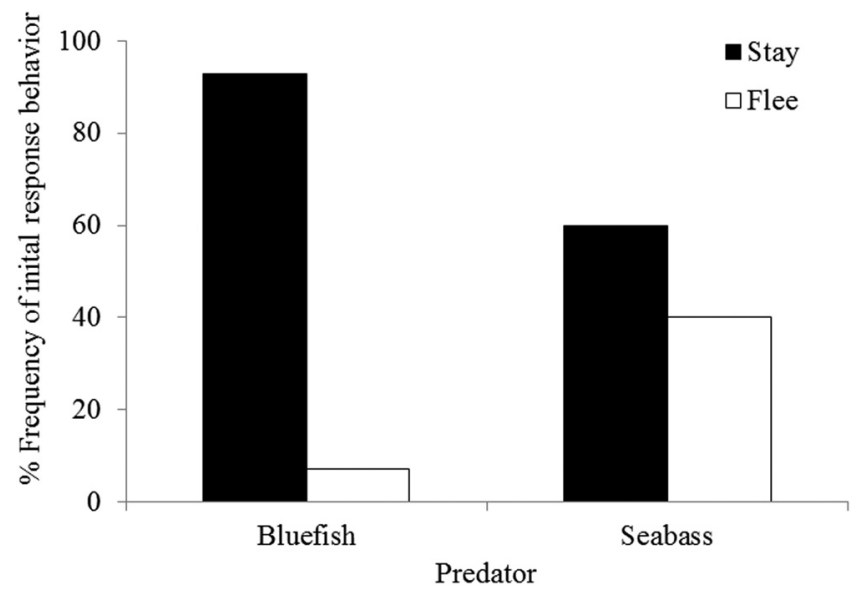

Figure 5. Percentage of stay (filled bar) or flee (open bar) tactics shown by cuttlefish as initial responses to approaches by seabass $(n=20$ behavioral sequences from 6 trials) and bluefish $(n=14$ behavioral sequences from 9 trials) during predator-prey trials. Note that initial responses were not evaluated during trials with flounder because no predatorprey interactions were observed. to deter seabass. When seabass approached cuttlefish, Dark mottle was the most common body pattern shown $(n=11)$, and flattened body $(n=2)$ and threat postures $(n=3)$ were the most common postures used (Table 2). After deimatic displays were initially shown, cuttlefish typically inked $(n=9)$ and used flight $(n=16)$ to maximize the distance between themselves and seabass within the tank (Fig. 7). During two predator-prey interactions, copious amounts of ink were released to form a smoke screen (Fig. 8C); cuttlefish hid in the ink until the predator swam away, then changed their body pattern to Light mottle, which matched the substrate, and slowly drifted away from the ink cloud (Video 2: Cuttlefish smoke screen, http://www.biolbull.org/ content/supplemental). Protean defenses (i.e., unpredictable behaviors) were used only occasionally with seabass $(n=$ 4) and included erratic jetting combined with pattern-flashing tactics (Fig. 7). Interestingly, primary defense (e.g., Background resemblance to match the substrate) was one of the least used tactics with seabass $(n=4)$.

\section{Bluefish}

Fourteen behavioral sequences were evaluated during the nine trials conducted with bluefish as predators. During trials, bluefish actively swam around the experimental tank in loose schools, and generally stayed in the lower to mid portion of the water column. Attacks by bluefish occurred in three separate trials; in two out of three of these instances, bluefish were successful in capturing and consuming cuttlefish. Bluefish detected and attacked cuttlefish that had recently changed their position on the substrate, but at the time of the attack were motionless and camouflaging on the bottom. During an attack, a single bluefish would change swimming speed relative to the other fish in the tank, angle its body downward, and bite the cuttlefish off the bottom. Bluefish did not complete the final phase of the attack sequence until they were less than one body length away from their target. Cuttlefish remained closely associated with the substrate during trials with bluefish; consequently, the vast majority of behavioral sequences took place on $(79 \%, 11 / 14)$ or near $(14 \%, 2 / 14)$ the bottom (Fig. 4). On only one occasion did cuttlefish swim near the surface of the water column, and this was after an attack had occurred.

Cuttlefish predominantly used stay tactics $(92.9 \%, 13 / 14)$ as initial responses to approaches and attacks by bluefish (Fig. 5). The most common stay behavior $(n=7)$ was for cuttlefish to remain motionless on the bottom while displaying a Light mottle body pattern that matched the substrate, even when bluefish swam directly above them (Fig. 6). Overall, cuttlefish relied more on the primary defense of crypsis during trials with bluefish $(n=14)$ than with seabass $(n=4$; Fig. 7), and were successful in avoiding detection by bluefish during three trials (e.g., no predator-prey interactions were observed). Body patterns that functioned 


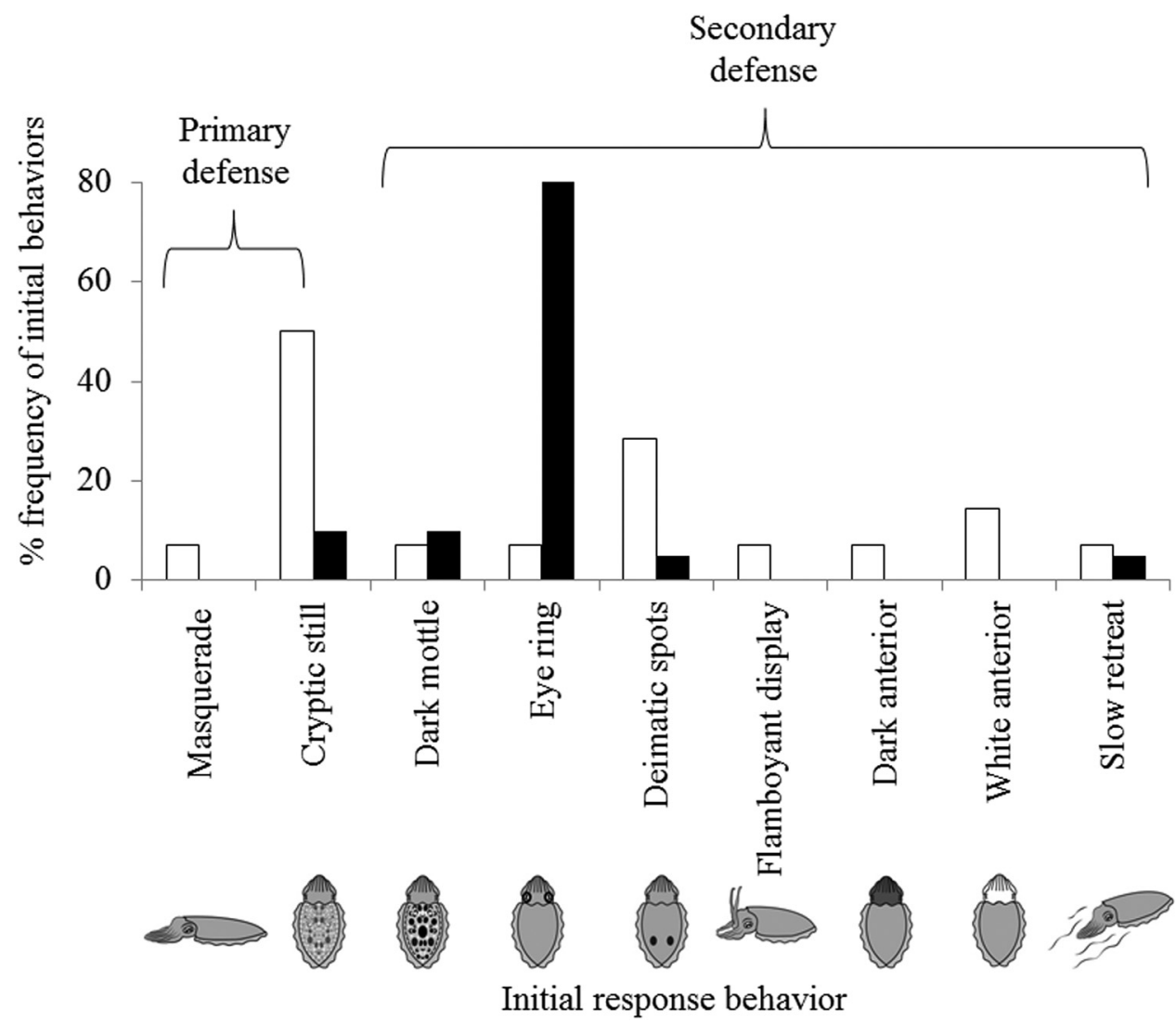

Figure 6. Relative frequency of initial response behaviors shown by cuttlefish to seabass (filled bar, $n=20$ behavioral sequences from 6 trials) and bluefish (open bar, $n=14$ sequences from 9 trials) predators during predator-prey trials. Initial response behaviors were not shown during flounder trials.

as deceptive resemblance or masquerade $(n=3)$ were observed only during bluefish trials (Table 2; Fig. 8D). In

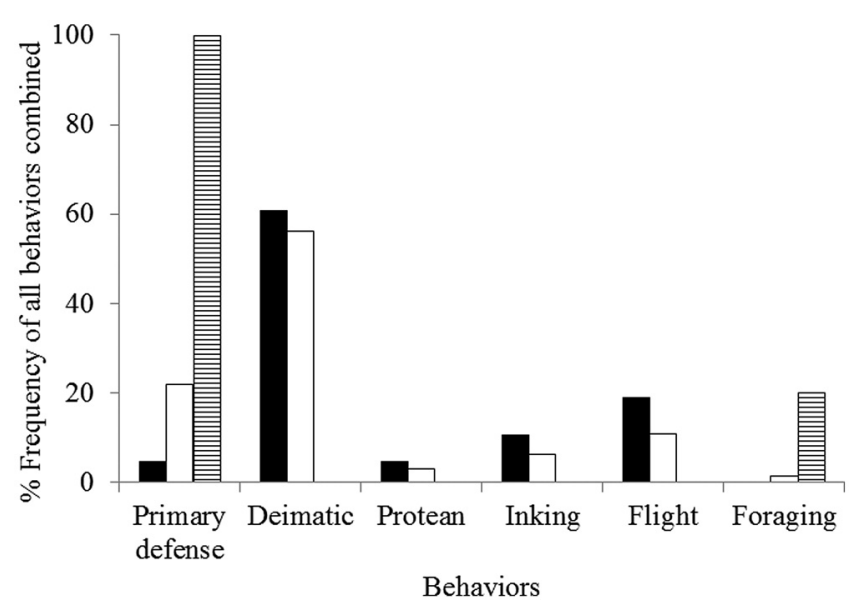

Figure 7. Relative frequencies of all primary and secondary defenses, as well as cuttlefish foraging behaviors shown during trials with seabass (filled bar, $n=22$ behavioral sequences from 6 trials); bluefish (open bar, $n=17$ sequences from 9 trials); and flounder (striped bar). Note that secondary defense behaviors were not observed during trials with flounder. some cases, it was unclear whether bluefish detected cuttlefish that were masquerading; in other instances, eye move-
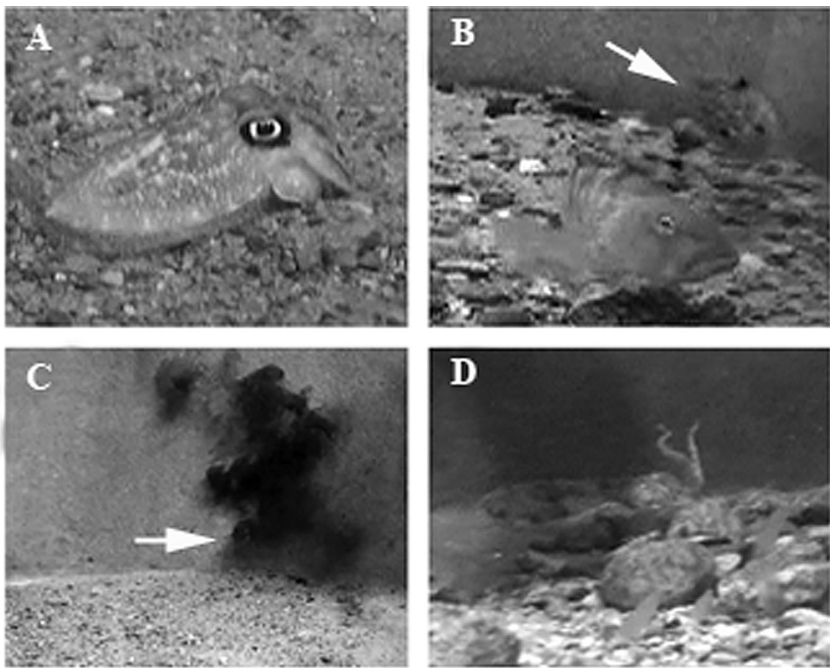

Figure 8. Video stills of cuttlefish showing (A) Dark eye ring, (B) Deimatic spots, (C) Ink smoke screen, and (D) Deceptive resemblance displays. Arrows point to cuttlefish location in B and C. 
ments and body orientation indicated that bluefish were investigating cuttlefish, yet they did not attack. It is unknown whether bluefish recognized cuttlefish as potential prey in these instances.

Similar to trials with seabass, in trials with bluefish deimatic defenses were the most common tactics $(n=36)$ used for secondary defense (Fig. 7). Deimatic spots with and without movement $(n=16)$, flamboyant postures (threat: $n=4$; flattened body: $n=2)$, Dark mottle $(n=4)$, and Dark eye ring $(n=4)$ were the most common displays used. During three interactions with bluefish, cuttlefish oriented their mantle or swam vertically in the water column with the posterior tip of the mantle pointing downward so that the Deimatic spots were directly in the line of sight of the approaching fish (Video 3: Cuttlefish false eye spots orient mantle, http://www.biobull.org/content/supplemental). In all but one of the three encounters, this behavior caused bluefish to abandon their approach and turn away; however, in the trial where bluefish completed the attack sequence, the cuttlefish still escaped after heavy inking. As was true with seabass, inking was not shown as an initial response to bluefish (Fig. 6), but was used $(n=4)$ in conjunction with flight $(n=7)$ when deimatic displays and primary defenses failed to deter bluefish and an attack was imminent (Video 2: cuttlefish smoke screen, http://www.biolbull.org/content/ supplemental).

During one bluefish trial, cuttlefish switched from a Light mottle body pattern to a pattern with Dark anterior head and arms while hovering just above the substrate; the cuttlefish then positioned itself as it used two of its arms to "walk" along the bottom (bipedal locomotion) as bluefish swam by. After bluefish passed and were on the opposite side of the tank, the cuttlefish flashed Dark arms while it seized and consumed a small crustacean living in the substrate, and then switched back to an Dark anterior head and arm display when bluefish swam near again (Video 4: Cuttlefish walking on the bottom, http://www.biolbull.org/content/supplemen tal).

\section{Summer flounder}

Ten trials were conducted using summer flounder as predators. Flounder remained camouflaged on the substrate during all trials and did not pursue or attack cuttlefish; however, in several trials, flounder exhibited a raised pectoral fin, indicating they were alert (Staudinger and Juanes, $2010 b, c)$. Throughout trials with flounder, cuttlefish stayed closely associated with the bottom, and remained in primary defense showing a Light mottle body pattern as they alternated between cryptic still and moving behaviors. Cuttlefish did not appear to be aware of flounders' presence in the experimental tank, as evidenced by the absence of secondary defenses such as deimatic and protean displays, inking, and flight. Cuttlefish spent the majority of the time on $(50 \%$,
$5 / 10)$ or hovering just above $(50 \%, 5 / 10)$ the substrate and never swam into the upper portion of the water column (Fig. 4). During two trials, cuttlefish were observed to forage on small crustaceans living in the substrate (Video 5: Cuttlefish foraging, http://www.biolbull.org/content/supplemental). When hunting, cuttlefish flashed the Dark anterior head and arm pattern on and off before making a tentacle strike and seizing prey; acute mottle was shown while prey were consumed (Fig. 7).

\section{Discussion}

Cuttlefish are known to show complex displays as antipredator defenses, sexual displays, hunting displays, and as alarm signals to conspecifics (Moynihan and Rodaniche, 1982; Hanlon and Messenger, 1988; Adamo and Hanlon, 1996; Adamo et al., 2006; Langridge et al., 2007). In control trials where no predators were present, cuttlefish showed several body patterns that camouflaged them against natural substrates consisting of sand, rocks, and pebbles. These body patterns were also observed in predator-prey trials. However secondary defenses consisting of acute chromatic, locomotor, and postural displays were shown only during trials with predatory fishes.

With seabass-a sit-and-pursue predator-cuttlefish used flight and spent more time swimming in the upper portion of the water column than during trials with bluefish and flounder. In addition, high-contrast Dark mottle body patterns were frequently shown to seabass in conjunction with the deimatic Dark eye ring display. Conversely, during trials with bluefish - an active searching predator-cuttlefish stayed close to the bottom, decreased movement, and showed body patterns and postures that camouflaged them amidst their surrounding environment. Because flounder did not pursue cuttlefish or make any attacks, we were unable to evaluate secondary defenses to a lie-and-wait predator. Cuttlefish appeared unaware of flounder's presence, and thus may be especially vulnerable to ambush predators. However, the fact that cuttlefish used primary defense (i.e., crypsis) at all times with flounder demonstrates that their behaviors are influenced by the pervasive risk of predation even when a threat is not apparent.

\section{The influence of predator traits and behaviors}

Predator traits such as body type, body size, and swimming speed have been shown to influence antipredator response behaviors of prey in a range of aquatic, marine, and terrestrial animals (Webb, 1984; Stuart-Fox et al., 2008; Domenici, 2010; Mather, 2010). Functional characteristics, such as hunting mode and the utilization of habitat space (e.g., whether predators stalk prey on the bottom or from the water column), are also important in determining how predators and prey interact (Schmitz, 2007). These factors influence decision-making, as prey assess the relative risk 
posed by an approaching (potential) predator and consequently choose which antipredator tactics (e.g., flee or stay) to use, or whether to engage in other activities such as foraging or mating (Lima and Dill, 1990).

We observed cuttlefish in the presence of bluefish to use behaviors similar to those that have been observed in previous laboratory experiments and in situ when related cephalopod species were confronted with roving teleost predators (Macy, 1982; Staudinger et al., 2011). During these types of encounters, cuttlefish and longfin squid (Doryteuthis pealeii) were reported to stay closely associated with the substrate and remain motionless until the threat had passed or an attack was initiated, followed by flight. Alternatively, in field experiments conducted by Hanlon and Messenger (1988), S. officinalis was observed in natural habitats to swim toward the surface when approached by the serranid Serranus cabrilla. This behavior was effective in stopping the pursuit of S. cabrilla, and was similar to the responses observed toward black seabass in the present study. Both serranid species closely associate and hunt for prey in demersal and benthic habitats (Labropoulou and Eleftheriou, 1997; Steimle et al., 1999; Gibran, 2007). In a laboratory experiment conducted by Langridge et al. (2007), S. officinalis also responded to S. cabrilla with deimatic displays followed by flight.

Collectively, observations made in the present study and previously published studies in the laboratory and field suggest that cephalopod defensive behaviors are highly species-specific (Hanlon and Messenger, 1988; Langridge et al., 2007; Staudinger et al., 2011). We hypothesize that, similar to longfin squid (Staudinger et al., 2011), cuttlefish may generally rely more on cryptic behaviors and reduce activity levels in the presence of active searching predators (e.g., bluefish) that are strong swimmers and can actively pursue them in the water column. However, cuttlefish will increase movement, and hence conspicuousness, when relatively sedentary or bottom-associated predators (e.g., serranids) are encountered and encroach in their preferred habitat (near the substrate). These types of predators are less agile swimmers and thus less likely to pursue and overcome cuttlefish (Nannini and Belk, 2006; Schmitz, 2007).

\section{Deimatic displays}

Deimatic displays that startle or bluff (Edmunds, 1974) have been shown to vary in their effectiveness in discouraging attacks by different predators (Lenzi-Mattos et al., 2005; Vallin et al., 2007; Staudinger et al., 2011). In the present study, the frequency, type, and order in which deimatic displays were shown by cuttlefish differed in the presence of seabass and bluefish predators. Cuttlefish were more likely to use Dark eye ring as an initial reaction to seabass, followed by flight, while Deimatic spots were almost always shown to bluefish after primary defense failed. Although these two displays are similar in appearance and function, it is uncertain why cuttlefish would use one over the other. One possible explanation is that Deimatic spots are shown more often to predators that have a higher likelihood of completing an attack even after being startled; thus if an attack ensues, it may be less damaging if it is directed toward the body of the cuttlefish (where its dorsally located cuttlebone protects the visceral organs) rather than the head. The use of Deimatic spots with movement, in this case orienting the mantle toward the approaching predator, has been described in previous studies and is thought to maximize the effect of this visual deimatic display (Young, 1950; Edmunds, 1974; Hanlon and Messenger, 1988; Vallin et al., 2007). This may also explain why the Deimatic spot display with movement was preferentially shown to bluefish, which represented a comparatively greater threat than seabass as evidenced by the greater proportion of interactions that ended in mortality or injury. Alternatively, because two cuttlefish were present during trials with seabass compared to one with bluefish, the Dark eye ring display may have been used as a signal to conspecifics to alert them of danger as well as an antipredator display, as has been suggested for Sepioteuthis sepioidea by Moynihan and Rodaniche (1982).

\section{Inking}

The ejection of ink is a common antipredator defense in marine molluscs (Derby, 2007). In shallow-water cephalopods, ink is thought to function primarily as a visual deterrent and is emitted in several forms, including pseudomorphs, plumes, and clouds (Hanlon and Messenger, 1996). Increasing evidence also suggests that ink acts as an alarm cue to conspecifics (Wood et al., 2008) and as a chemical deterrent against predators (Bush and Robison, 2007; Wood et al., 2010). Similar to the findings of Langridge (2009), inking in our study was typically used in conjunction with erratic jetting or flight. In our experiments, cuttlefish released large ink clouds, commonly referred to as smoke screens, which they hid behind during trials with bluefish and seabass. Smoke screens were always effective in enabling cuttlefish to escape predation. On one occasion, inking was effective in causing bluefish to release cuttlefish during the capture phase of an attack. Our results provide additional support that ink increases the ability of cephalopods to escape predators via this protean tactic (Hanlon and Messenger, 1996; Wood et al., 2010; Staudinger et al., 2011), but do not clarify whether ink acts as a chemical deterrent as well as a visual cue. Despite its effectiveness against predators, both in the present study and in a related study using longfin squid (Staudinger et al., 2011), inking was used less often than deimatic displays and flight. This is possibly due to the relatively high metabolic cost of pro- 
ducing and expelling ink in combination with mucus and melanin (Russo et al., 2003).

\section{Cuttlefish foraging-related behaviors}

Previous studies have shown that cuttlefish and other cephalopods (e.g., Sepiola affinis) sometimes exhibit conspicuous body pattern displays while foraging (e.g., Passing cloud; Dark arms); these behaviors are thought to function similarly to deimatic displays - to startle or distract prey just prior to and during capture (Mauris, 1989; Adamo et al., 2006). In the present study, cuttlefish showed different body patterns and behaviors during trials when predators were apparent (with bluefish) than when they were not (with flounder). Adamo et al. (2006) reported similar results after cuttlefish were exposed to a (model) predator compared to when animals were allowed to forage without a disturbance. Bipedal locomotion was shown by cuttlefish during a single trial with bluefish; previously, this behavior has been reported only in the two octopus species Abdopus aculeatus and Amphioctopus marginatus (Huffard et al., 2005; Huffard, 2006). Huffard (2006) suggested that bipedal locomotion may allow octopus to move cryptically and deceive predators by taking a form that inhibits recognition as prey (e.g., as algae); this could be considered a form of masquerade (Skelkorn et al., 2010). While Huffard (2006) observed octopus to use bipedal locomotion during rapid escape from a disturbance, cuttlefish used slow movements and bipedal locomotion when hunting in the presence of bluefish. We agree with Huffard (2006) that bipedal locomotion combined with a cryptic body pattern may function as a form of primary defense to escape detection by predators. However, since this behavior was observed only on a single occasion with cuttlefish, more studies are needed to determine its function.

\section{Conclusions}

While our results suggest that cuttlefish use different camouflage and defense behaviors in the absence and presence of different types of predators, findings should be considered qualitative and preliminary as there were several factors that we were not able to control during trials. Limited numbers of cuttlefish made it necessary to reuse individuals in multiple trials, thus behavioral responses to predators should not be considered those of naïve animals. Nonetheless, the frequency with which cuttlefish were used in trials was likely not often enough (about once every 4 weeks, and once with each type of predator) for them to adapt to the experimental design and predators; nonetheless, we do not know what effect reuse had on defense behaviors over the course of all trials. During predator-prey trials, there were no barriers separating cuttlefish from fish predators and thus no control on how close a predator could approach. Because we did not measure the reaction distance of cuttlefish to predators, we do not know how much this varied among predator species or predation strategies and influenced cuttlefish defense behaviors. Additional studies measuring flight initiation distance are still needed to draw conclusions on the role predation tactics play in evoking flight and other defense behaviors (Stankowich and Blumstein, 2005). Moreover, several months elapsed between trials with each type of predator, and during this time cuttlefish grew. There is evidence that the responses of younger individuals may differ from those of adults (Hanlon and Messenger, 1988; Staudinger and Juanes, 2010c) and could have influenced the types of behaviors shown toward different predators.

The oversimplified environment of the experimental arena and lack of vertical structures also likely influenced cuttlefish and fish behaviors in our experiments (Michel and Adams, 2009). For example, deceptive resemblance or masquerade was observed only four times over the course of all 25 trials. Masquerade is commonly used by cuttlefish, squid, and octopods to avoid detection or recognition by predators by resembling objects in their immediate environment such as rocks, seaweed, and other animals (Packard and Sanders, 1971; Hanlon et al., 1999, 2008; Buresch et al., 2011). In addition, deimatic defenses may have been heightened relative to other tactics due to the close confinement of predators and prey and the limited escape potential that cuttlefish would have access to in the wild (Holmes, 1940; Hanlon and Messenger, 1988).

Despite these limitations, observations of predation in the wild are rare (Hanlon and Messenger, 1988; Boland, 2003; Mather, 2010), thus laboratory experiments provide a useful opportunity to gain a better understanding of when and how cephalopods vary their behaviors in response to different threats. Surprisingly few studies have evaluated cephalopod antipredator tactics in response to real predators, and those that do exist have produced inconsistent results. For example, Langridge (2009) concluded that S. officinalis does not show deimatic displays toward large predatory teleosts, whereas deimatic displays were some of the most common tactics used by $S$. officinalis in the present study, as well as by longfin squid in Staudinger et al. (2011). These differences between studies likely reflect different experimental designs. For example, Langridge (2009) used a plastic barrier to separate predators from prey, whereas in the present study and in Staudinger et al. (2011) barriers were omitted to simulate natural predator-prey encounters. To resolve these discrepancies and better understand how cephalopods assess predation risk, future studies should focus on field observations in natural habitats and on experimental designs that provide greater habitat complexity (e.g., vertical structures such as vegetation and rocks) and increased space, allow for larger schools of predators, and evaluate simultaneous interactions with multiple species of predators. 


\section{Acknowledgments}

This project was funded by a United States Department of Defense, Defense Advanced Research Projects Agency, Defense Sciences Office (DARPA DSO) Grant (HR0011-091-0017). Results do not necessarily reflect the position or the policy of the U.S. Government and are not endorsed by the Department of Defense. Experiments were conducted according to an IACUC approved protocol (MBL 09-16). We thank R. Probyn, the Captain and crew of the RV Gemma for collecting fish, L. Siemann for assistance with rearing and caring for cuttlefish, and Aquatic Resources Division staff of MBL for help with care of fish and cuttlefish.

\section{Literature Cited}

Adamo, S. A., and R. T. Hanlon. 1996. Do cuttlefish (Cephalopoda) signal their intentions to conspecifics during agonistic encounters? Anim. Behav. 52: 73-81.

Adamo, S. A., K. Ehgoetz, C. Sangster, and I. Whitehorne. 2006. Signaling to the enemy? Body pattern expression and its response to external cues during hunting in the cuttlefish Sepia officinalis (Cephalopoda). Biol. Bull. 210: 192-200.

Barbosa, A., C. F. Florio, C.-C. Chiao, and R. T. Hanlon. 2004. Visual background features that elicit mottled body patterns in cuttlefish, Sepia officinalis. Biol. Bull. 207: 154.

Barbosa, A., L. M. Mäthger, C. Chubb, C. Florio, C.-C. Chiao, and R. T. Hanlon. 2007. Disruptive coloration in cuttlefish: a visual perception mechanism that regulates ontogenetic adjustment of skin patterning. J. Exp. Biol. 210: 1139-1147.

Barbosa, A., L. M. Mäthger, K. C. Buresch, J. Kelly, C. Chubb, C.-C. Chiao, and R. T. Hanlon. 2008. Cuttlefish camouflage: the effects of substrate contrast and size in evoking uniform, mottle or disruptive body patterns. Vision Res. 48: 1242-1253.

Barbosa, A., J. J. Allen, L. M. Mäthger, and R. T. Hanlon. 2012. Cuttlefish use visual cues to determine arm postures for camouflage. Proc. R. Soc. B. Biol. Sci. 279: 84-90.

Blanc, A., and J. Daguzan. 2000. Size selectivity in the diet of the young cuttlefish Sepia officinalis (Mollusca: Sepiidae). J. Mar. Biol. Assoc. UK 80: 1137-1138.

Boland, C. R. J. 2003. An experimental test of predator detection rates using groups of free-living emus. Ethology 109: 209-222.

Broom, M., and G. D. Ruxton. 2005. You can run-or you can hide: optimal strategies for cryptic prey against pursuit predators. Behav. Ecol. 16: 534-540.

Buresch, K. C., L. M. Mäthger, J. J. Allen, C. Bennice, N. Smith, J. Schram, C.-C. Chiao, C. Chubb, and R. T. Hanlon. 2011. The use of background matching vs. masquerade for camouflage in cuttlefish Sepia officinalis. Vision Res. 51: 2362-2368.

Bush, S. L., and B. H. Robison. 2007. Ink utilization by mesopelagic squid. Mar. Biol. 152: 485-494.

Chiao, C.-C., and R. T. Hanlon. 2001. Cuttlefish camouflage: visual perception of size, contrast and number of white squares on artificial checkerboard substrata initiates disruptive coloration. J. Exp. Biol. 204: 2119-2125.

Chiao, C.-C., C. Chubb, K. Buresch, L. Siemann, and R. T. Hanlon. 2009. The scaling effects of substrate texture on camouflage patterning in cuttlefish. Vision Res. 49: 1647-1656.

Chiao, C.-C., C. Chubb, K. C. Buresch, A. Barbosa, J. J. Allen, L. M. Mäthger, and R. T. Hanlon. 2010. Mottle camouflage patterns in cuttlefish: quantitative characterization and visual background stimuli that evoke them. J. Exp. Biol. 213: 187-199.

Cott, H. B. 1940. Adaptive Coloration in Animals. Methuen, London.

Derby, C. D. 2007. Escape by inking and secreting: marine molluscs avoid predators through a rich array of chemicals and mechanisms. Biol. Bull. 213: 274-289.

Domenici, P. 2010. Context-dependent variability in the components of fish escape response: integrating locomotor performance and behavior. J. Exp. Zool. 313A: 59-79.

Domenici, P., D. Booth, J. M. Blagburn, and J. P. Bacon. 2008. Cockroaches keep predators guessing by using preferred escape trajectories. Curr. Biol. 18: 1792-1796.

Driver, P. M., and D. A. Humphries. 1988. Protean Behaviour: The Biology of Unpredictability. Oxford University Press, New York.

Edmunds, M. 1974. Defense in Animals. A Survey of Anti-predator Defenses. Longman Group, New York.

Endler, J. A. 1991. Interactions between predators and prey. Pp. 169196 in Behavioural Ecology: An Evolutionary Approach, J. R. Krebs and N. B. Davies, eds. Blackwell Scientific, Oxford.

Gibran, F. Z. 2007. Activity, habitat use, feeding behavior, and diet of four sympatric species of Serranidae (Actinopterygii: Perciformes) in southeastern Brazil. Neotrop. Ichthol. 5: 387-398.

Hanlon, R. T., and J. B. Messenger. 1988. Adaptive coloration in young cuttlefish (Sepia officinalis L.): the morphology and development of body patterns and their relation to behaviour. Philos. Trans. $R$. Soc. B. Biol. Sci. 320: 437-487.

Hanlon, R. T., and J. B. Messenger. 1996. Cephalopod Behaviour. Cambridge University Press, Cambridge.

Hanlon, R. T., J. W. Forsythe, and D. E. Joneschild. 1999. Crypsis, conspicuousness, mimicry and polyphenism as antipredator defences of foraging octopuses on Indo-Pacific coral reefs, with a method of quantifying crypsis from video tapes. Biol. J. Linn. Soc. 66: 1-22.

Hanlon R. T., L. A. Conroy, and J. W. Forsythe. 2008. Mimicry and foraging behaviour of two tropical sand-flat octopus species off North Sulawesi, Indonesia. Biol. J. Linn. Soc. 93: 23-38.

Holmes, W. 1940. The colour changes and colour patterns of Sepia officinalis L. Proc. Zool. Soc. Lond. A 110: 2-35.

Hoverman, J. T., and R. A. Relyea. 2007. The rules of engagement: how to defend against combinations of predators. Oecologia 154: $551-560$

Huffard, C. L. 2006. Locomotion by Abdopus aculeatus (Cephalopoda: Octopodidae): walking the line between primary and secondary defenses. J. Exp. Biol. 209: 3697-3707.

Huffard, C. L., F. Boneka, and R. J. Full. 2005. Underwater bipedal locomotion by octopuses in disguise. Science 307: 1927.

Humphries, D. A., and P. M. Driver. 1970. Protean defense by prey animals. Oecologia 5: 285-302.

Juanes, F., and D. O. Conover. 1994. Piscivory and prey size selection in young-of-the-year bluefish: predator preference or size-dependent capture success? Mar. Ecol. Prog. Ser. 114: 59-69.

Juanes, F., J. A. Hare, and A. G. Miskiewicz. 1996. Comparing early life history strategies of Pomatomus saltatrix: a global approach. Mar. Freshw. Res. 47: 365-379.

Kelman, E. J., R. J. Baddeley, A. J. Shohet, and D. Osorio. 2007. Perception of visual texture and the expression of disruptive camouflage by the cuttlefish, Sepia officinalis. Proc. R. Soc. B. Biol. Sci. 274:1369-1375.

Kelman, E. J., D. Osorio, and R. J. Baddeley. 2008. A review of cuttlefish camouflage and object recognition and evidence for depth perception. J. Exp. Biol. 211: 1757-1763.

Labropoulou, M., and A. Eleftheriou. 1997. The foraging ecology of two pairs of congeneric demersal fish species: importance of morphological characteristics in prey selection. J. Fish Biol. 50: 324-340. 
Langridge, K. V. 2009. Cuttlefish use startle displays, but not against large predators. Anim. Behav. 77: 847-856.

Langridge, K. V., M. Broom, and D. Osorio. 2007. Selective signaling by cuttlefish to predators. Curr. Biol. 17: R1044-R1045.

Lenzi-Mattos, R., M. M. Antoniazzi, C. F. B. Haddad, D. V. Tambourgi, M. T. Rodrigues, and C. Jared. 2005. The inguinal macroglands of the frog Physalaemus nattereri (Leptodactylidae): structure, toxic secretion and relationship with deimatic behaviour. J. Zool. 266: $385-394$

Lima, S. L., and L. M. Dill. 1990. Behavioral decisions made under the risk of predation: a review and prospectus. Can. J. Zool. 68: 619-640.

Lipinski, M. R., and S. Jackson. 1989. Surface-feeding on cephalopods by procellariiform seabirds in the southern Benguela region, South Africa. J. Zool. 218: 549-563.

Macy, W. K. 1982. Feeding patterns of the long-finned squid, Loligo pealei, in New England waters. Biol. Bull. 162: 28-38.

Mather, J. A. 2010. Vigilance and antipredator responses of Caribbean reef squid. Mar. Freshw. Behav. Physiol. 43: 357-370.

Mäthger, L. M., A. Barbosa, S. Miner, and R. T. Hanlon. 2006. Color blindness and contrast perception in cuttlefish (Sepia officinalis) determined by a visual sensorimotor assay. Vision Res. 46: 1746-1753.

Mäthger, L. M., C.-C. Chiao, A. Barbosa, K. C. Buresch, S. Kaye, and R. T. Hanlon. 2007. Disruptive coloration elicited on controlled natural substrates in cuttlefish, Sepia officinalis. J. Exp. Biol. 210: 2657-2666.

Mäthger, L. M., C.-C. Chiao, A. Barbosa, and R. T. Hanlon. 2008. Color matching on natural substrates in cuttlefish, Sepia officinalis. J. Comp. Physiol. A 194: 577-585.

Mäthger, L. M., G. R. R. Bell, A. M. Kuzirian, J. J. Allen, and R. T. Hanlon. 2012. How does the blue-ringed octopus (Hapalochlaena lunulata) flash its blue rings? J. Exp. Biol. 215: 3752-3757.

Mauris, E. 1989. Colour patterns and body postures related to prey capture in Sepiola affinis (Mollusca, Cephalopoda). Mar. Behav. Physiol. 14: 189-200.

Michel, M. J., and M. M. Adams. 2009. Differential effects of structural complexity on predator foraging behavior. Behav. Ecol. 20: 313317.

Moynihan, M., and A. F. Rodaniche. 1982. The behavior and natural history of the Caribbean reef squid Sepioteuthis sepiodea. With a consideration of social, signal and defensive patterns for difficult and dangerous environments. Adv. Ethology 25: 1-151.

Muus, B. J., and J. G. Nielsen. 1999. Sea Fish. Scandinavian Fishing Year Book, Hedehusene, Denmark.

Nannini, M. A., and M. C. Belk. 2006. Antipredator responses of two native stream fishes to an introduced predator: Does similarity in morphology predict similarity in behavioural response? Ecol. Freshw. Fish 15: 453-463.

Packard, A. 1972. Cephalopods and fish: the limits of convergence. Biol. Rev. 47: 241-307.

Packard, A., and G. D. Sanders. 1971. Body patterns of Octopus vulgaris and maturation of the response to disturbance. Anim. Behav. 19: $780-790$

Robinson, M. H. 1969. Defenses against visually hunting predators. Pp. 225-259 in Evolutionary Biology 3, T. Dobzhansky, M. K. Hecht, and W. C. Steere, eds. Meredith, New York.

Russo, G. L., E. De Nisco, G. Fiore, P. Di Donato, M. d'Ischia, and A. Palumbo. 2003. Toxicity of melanin-free ink of Sepia officinalis to transformed cell lines: identification of the active factor as tyrosinase. Biochem. Biophys. Res. Commun. 308: 293-299.

Scharf, F. S., J. A. Buckel, F. Juanes, and D. O. Conover. 1998. Predation by juvenile piscivorous bluefish (Pomatomus saltatrix): the influence of prey to predator size ratio and prey type on predator capture success and prey profitability. Can. J. Fish. Aquat. Sci. 55: 1695-1703.

Scharf, F. S., F. Juanes, and R. A Rountree. 2000. Predator size-prey size relationships of marine fish predators: interspecific variation and effects of ontogeny and body size on trophic niche breadth. Mar. Ecol. Prog. Ser. 208: 229-248.

Schmitz, O. J. 2005. Behavior of predators and prey and links with population level processes. Pp. 256-278 in Ecology of Predator-Prey Interactions, P. Barbosa and I. Castellanos, eds. Oxford University Press, Oxford.

Schmitz, O. J. 2007. Predator diversity and trophic interactions. Ecology 88: $2415-2426$.

Skelhorn, J., H. M. Rowland, M. P. Speed, and G. D. Ruxton. 2010. Masquerade: camouflage without crypsis. Science 327: 51.

Stankowich, T., and D. T. Blumstein. 2005. Fear in animals: a metaanalysis and review of risk assessment. Proc. R. Soc. B. Biol. Sci. 272: $2627-2634$.

Staudinger, M. D. 2006. Seasonal and size-based predation on two species of squid by four fish predators on the northwest Atlantic continental shelf. Fish. Bull. 104: 605-615.

Staudinger, M. D., and F. Juanes. 2010a. A size-based approach to quantifying predation on longfin inshore squid (Loligo pealeii) in the northwest Atlantic. Mar. Ecol. Prog. Ser. 399: 225-241.

Staudinger, M., and F. Juanes. 2010b. Feeding tactics of a behaviorally plastic predator, summer flounder (Paralichthys dentatus). J. Sea Res. 64: $68-75$

Staudinger, M. D., and F. Juanes. 2010c. Size-dependent susceptibility of longfin inshore squid (Loligo pealeii) to attack and capture by two predators. J. Exp. Mar. Biol. Ecol. 393: 106-113.

Staudinger, M. D., R. T. Hanlon, and F. Juanes. 2011. Primary and secondary defenses of squid to cruising and ambush fish predators: variable tactics and their survival value. Anim. Behav. 81: 585-594.

Steimle, F. W., C. A. Zetlin, P. L. Berrien, and S. Chang. 1999. Essential fish habitat source document: Black sea bass, Centropristis striata, life history and habitat characteristics. NOAA Technical Memo NMFS-NE-143, National Marine Fisheries Service, Woods Hole, MA. $50 \mathrm{pp}$.

Stuart-Fox, D., A. Moussalli, and M. J. Whiting. 2008. Predatorspecific camouflage in chameleons. Biol. Lett. 4: 326-329.

Vallin, A., S. Jakobsson, and C. Wiklund. 2007. "An eye for an eye?"- on the generality of the intimidating quality of eyespots in a butterfly and a hawkmoth. Behav. Ecol. Sociobiol. 61: 1419-1424.

Webb, P. W. 1984. Body form, locomotion and foraging in aquatic vertebrates. Am. Zool. 24: 107-120.

Wood, J. B., K. E. Pennoyer, and C. D. Derby. 2008. Ink is a conspecific alarm cue in the Caribbean reef squid, Sepioteuthis sepioidea. $J$ Exp. Mar. Biol. Ecol. 367: 11-16.

Wood, J. B., A. E. Maynard, A. G. Lawlor, E. K. Sawyer, D. M. Simmons, K. E. Pennoyer, and C. D. Derby. 2010. Caribbean reef squid, Sepioteuthis sepioidea, use ink as a defense against predatory French grunts, Haemulon flavolineatum. J. Exp. Mar. Biol. Ecol. 388: $20-27$.

Young, J. Z. 1950. The Life of Vertebrates. Oxford University Press, Oxford.

Zylinski, S., D. Osorio, and A. J. Shohet. 2009a. Edge detection and texture classification by cuttlefish. J. Vis. 9: 1-10.

Zylinski, S., D. Osorio, and A. J. Shohet. 2009b. Perception of edges and visual texture in the camouflage of the common cuttlefish, Sepia officinalis. Philos. Trans. R. Soc. B. Biol. Sci. 364: 439-448. 